\title{
Bargaining over power When do shifts in power lead to war?
}

\section{Journal Article}

\section{Author(s):}

Chadefaux, Thomas

Publication date:

2011-06

Permanent link:

https://doi.org/10.3929/ethz-b-000041138

\section{Rights / license:}

In Copyright - Non-Commercial Use Permitted

\section{Originally published in:}

International Theory 3(2), https://doi.org/10.1017/S175297191100008X 


\title{
Bargaining over power: when do shifts in power lead to war?
}

\author{
THOMAS CHADEFAUX \\ Department of Humanities, Social and Political Sciences, ETH Zurich, Zurich, Switzerland \\ E-mail: thomasc@ethz.ch
}

\begin{abstract}
Students of international relations have long argued that large and rapid shifts in relative power can lead to war. But then why does the rising state not alleviate the concerns of the declining one by reducing its expected future power, so that a commitment problem never emerges? For example, states often limit their ability to launch preemptive attacks by creating demilitarized zones, or they abandon armament programs to avoid preventive wars. In a model of complete information, I show that shifts in power never lead to war when countries can negotiate over the determinants of their power. If war occurs, then, it must be that negotiations over power are impossible or too costly. I then show how third parties, domestic politics, and problems of fungibility can increase the costs of such negotiations, and hence lead to war, even under complete information.
\end{abstract}

Keywords: conflict; causes of war; bargaining; power; war; power shifts

Students of international relations have long argued that rapid shifts in relative power can lead to war. 'The growth of Athenian power and the fear which this caused in Sparta' or the rise of Germany, for example, are common explanations for the Peloponnesian war and World War I, respectively. ${ }^{1}$ More recently, the economic and military rise of China has led many to wonder about the likelihood of a war with its neighbors or the United States. ${ }^{2}$ In each case, the declining state fears that it will negotiate in a position of weakness once the balance of power has shifted,

1 The quote is from Thucydides (1984). The rise of Germany as a cause for World War I is discussed in Joll (1992), and with a twist, in Ferguson (1999, 83): 'The key to the arms race before 1914 is that one side lost it, or believed that it was losing it. It was this belief which persuaded its leaders to gamble on war before they fell too far behind'. See also Ferguson (2006).

2 See, for example, Hoge (2004), Bijian (2005), or Mearsheimer (2006). 
and hence it is argued, prefers fighting now. The problem is not that there are no peaceful solutions that both parties would prefer to war; the costs and risks of war ensure that there always exists such an agreement. ${ }^{3}$ Rather, fighting occurs because any commitment to a specific course of action once the balance of power has shifted is inherently non-credible.

This line of argument, however, is problematic. If indeed rapid changes in relative power lead to inefficient conflicts, then why do states not negotiate over the causes and speed of this shift. In other words, why would the rising state not offer today concessions of capabilities that reduce his expected power tomorrow? Abandoning a weapons program or withdrawing troops from the border, for example, are simple ways to alter expected incentives in the next period, and hence to credibly commit to a specific course of action.

In other words, a credible commitment mechanism exists in a broad class of bargaining situations. Expectations are based on present attributes (e.g. a battleship program), which can be objects of negotiation themselves. By changing these attributes today, the rising state can tie his hands in the next period, and hence alleviate the declining state's concerns.

Unfortunately, most existing bargaining models have taken power as exogenous. In them, two states negotiate over a pie, given a certain distribution of power. Yet, countries interacting over time are likely to bargain not only over final outcomes but also over the means to obtain them - in short, over power itself. Indeed, a cursory look at history shows that states often do bargain over the determinants of their power. For example, they negotiate over their possession of weapons (see the recent crises with Iraq and Iran or the SALT agreements) and the positioning thereof (the Cuban missile crisis); they sometimes create demilitarized zones (the German Rhineland in 1919) or withdraw troops from the border, thereby limiting their ability to launch a successful offensive attack (India and Pakistan in 2002). At a deeper level, they exchange territories (the 1772 partition of Poland) or prevent power shifts by pooling their resources (e.g. the European Community of Coal and Steel).

I analyze a model of sequential bargaining with complete information in which power can shift over time, and actors bargain not only over the division of a pie but also over their power. Throughout, the central concern will be efficiency: when do large and rapid changes in relative power lead bargaining to break down into war? Complete information is assumed - not because it is a realistic assumption, but because it allows us

3 This is assuming, of course, that war is costly. This excludes from the analysis situations in which war is desired for its own sake. For example, diversionary wars can strengthen leaders (Russett 1990). 
to isolate theoretical effects more clearly than by adding mechanisms based on uncertainty. Section 'Related literature' reviews the relevant literature. In section 'Negotiating over power', I extend the typical commitment problem model by adding the ability to negotiate over future bargaining power, and show that war never occurs in equilibrium. I then analyze a number of extensions that can lead to war. Finally, section 'Negotiating over power in practice' elaborates on a number of historical cases illustrating the logic of the argument.

\section{Related literature}

Large and rapid changes in relative power are perhaps the most common explanation for war. Taylor $(1954,166)$, for example, notes that 'every war between Great Powers [between 1848 and 1918] started out as a preventive war'. As a result, a very large literature has analyzed the relationship between shifts in power and war. Organski (1958), for example, argues that rapid economic development driven by industrialization changes the distribution of power more rapidly than the existing international order, and hence leads to tensions. ${ }^{4}$ More recently, Morrow and Kim (1992), Fearon (1995), and Powell (1999, 2004, 2006) have provided more formal and general explanations for why bargaining might fail when relative power changes quickly. ${ }^{5}$ All these works emphasize the idea that rapid shifts in power generate fear in the declining state - fear caused by the inability of the rising state to commit to a specific partition of the pie once the shift has occurred. Yet, none of these theories solve the puzzle specified in the introduction: if indeed shifts in power lead to inefficient conflicts, then why does the rising state not offer today concessions of capabilities that will reduce his expected power tomorrow? ${ }^{6}$

To solve the puzzle, we need a model in which actors can bargain over power itself. Unfortunately, very few authors have treated power endogenously. A notable exception is Fearon (1996) who, in a related paper, analyzes a model in which actors bargain over objects that affect their future bargaining power. In his model, Fearon finds that war never occurs because one state always makes demands sufficiently small for the other state to prefer granting them than fighting. As I show later, however, this result holds only under the assumption that both players have equal

${ }^{4}$ A related argument is found in Gilpin (1981). See also Kim (1992) and Dicicco and Levy (1999).

${ }^{5}$ A historical survey of preventive wars can be found in Vagts (1956, 263-350); a good presentation of theories relating power shifts and war is Van Evera (1999).

${ }^{6}$ Fearon (1995) mentions this possibility, but does not elaborate. 
discount factors. In other words, bargaining over objects that affect future bargaining power can fail if one state values the future more than the other. In addition, I also show that introducing more than two players in the bargaining game can also lead to inefficient outcomes.

More applied strands of the literature have indirectly addressed the question of negotiations over power. North and Weingast (1989) and Acemoglu and Robinson (2000) argue that domestic commitment problems can be solved by transfers of political power - whether they take the form of a representative parliament or of an extended franchise. In both cases, risks of bargaining breakdowns today are prevented by concessions that allow the weaker player to have a say in the next period. Similarly, the literature on the time inconsistency problem has typically focused on the need to delegate monetary policy authority to an autonomous institution in order to credibly commit to a specific course of action (Kydland and Prescott 1977). Finally, a more empirical literature on civil war has also emphasized the role of power sharing as a commitment mechanism. For example, agreements that include provisions for sharing or dividing military power among former enemies improve the prospects for peace (Walter 2002; Hoddie and Hartzell 2003). Similarly, institutional arrangements can offer credible guarantees to former enemies as they move toward a situation of centralized state power (Hartzell 1999). These mechanisms are all related. Power transfers, whether to a central bank or rebels, are necessary to ensure the credibility of the commitment. Of interest here is a general analysis of the conditions under which such negotiations over power are possible, and of the assumptions required for such a result to hold.

Finally, a number of scholars have recently hinted at the possibility to negotiate over these shifts in power, in a way that might potentially prevent war. Fearon $(1995,407-408)$, in particular, mentions this possibility, but his conjecture is not proved formally and the argument actually requires important additional assumptions to hold. His paper also does not mention the potential difficulties associated with such a mechanism. Similarly, Reiter (2009) and Wagner (2007) also offer excellent discussions of the commitment problem and its possible solutions, but do not formalize their arguments either, so that many new insights and refinements are missed. In particular, section 'Why war might still occur' shows the potential complexity and caveats of negotiating over capabilities. Wolford et al. (2007) do formalize a related model on commitment problems, but their focus is on the interaction of the commitment and the informational problems - not on potential mechanisms to avoid commitment problems. Another related work is Philipp Fuerst's interesting work on ways by which the rising state can alleviate the fears of the 
declining one (Fuerst 2009). However, his model focuses on extending the commitment problem model with incomplete information in the form of signals and uncertainty, whereas the goal of the present paper is to investigate the conditions under which commitment problems can be avoided and the difficulties to do so, even under complete information.

\section{Negotiating over power}

This section proceeds in three main steps. I first review the commitment problem as it is traditionally understood in the literature. I then add the ability for states to negotiate over the determinants of their relative power and show that war never occurs in equilibrium. Finally, I illustrate the theoretical mechanism with historical examples.

\section{A commitment problem}

I first review the logic of the commitment problem, namely the idea that large and rapid shifts in power can lead to war despite complete information. The intuition is straightforward. Suppose, for example, that a country $A$ expects another country $B$ to grow stronger in the next period. Then, $A$ anticipates that $B$ will want a larger share of the territory tomorrow, and when the shift is large and rapid, no concessions from $B$ can satisfy $A$. As a result, $A$ prefers fighting now before $B$ becomes stronger.

To see this more formally, consider the following model. Two players (or 'states'), $A$ and $B$, negotiate in two successive periods over the occupation of a territory $X$ of size one. Let $\left(x^{0}, 1-x^{0}\right), x^{0} \in[0,1]$ denote the partition of $X$ at the beginning of the game (i.e. $A$ controls $x^{0}$ and $B$ controls $1-x^{0}$ ). In each period $(t=1,2)$, player $A$ makes an offer $x^{t} \in[0,1]$ to player $B$, where $x^{t}$ denotes the share of the territory that $A$ would receive (and $B$ would receive $1-x^{t}$ ). When convenient, I will use a subscript to denote the share each player obtains. Thus, $x_{A}^{t} \equiv x^{t}$ and $x_{B}^{t} \equiv 1-x^{t}$. B observes the offer, and either accepts or rejects it. If $B$ rejects offer $x^{t}$, then 'war' starts. War is a lottery in which $A$ wins the present and future use of the entire territory $X$ with the probability $p(t)$, where $p^{\prime}(t) \geqslant 0$. Both states incur a onetime loss of utility (a 'cost of war') of size $c_{i}>0$, and the game ends after the war and the allocation of payoffs. If, instead, $B$ accepts the offer, then the players occupy their respective shares of the territory, $x^{t}$ for $A$ and $1-x^{t}$ for $B$, until the end of the period. Period 2 starts immediately at the end of period 1 , and the game ends at the end of period 2 .

Payoffs. Let $u_{i}: X \rightarrow[0,1]$ be a continuous function that denotes player $i$ 's payoff for occupying a share of territory $x \in X$. For $i=A, B$ and for all $x \in X$, I assume $u_{i}^{\prime}(x)>0$ (monotonicity), $u_{i}^{\prime \prime}(x) \leqslant 0$ (non-risk acceptance), 
and I normalize $u(0)=0$ and $u(1)=1$. Finally, let $\delta_{i}$ denote player $i$ 's $(i=A, B)$ discount factor. Player $i$ 's utility for the overall game, then, is defined as

$$
U_{i}=u_{i}\left(x_{i}^{1}\right)+\delta_{i} u_{i}\left(x_{i}^{2}\right)
$$

We can now write player $i$ 's expected utility for a war starting at time $t$ as

$$
p_{i}^{t} \sum_{t}^{2} \delta^{t-1}-c_{i}
$$

where $p_{A}^{t}=p(t)$ and $p_{B}^{t}=1-p(t)$. All elements of the game are common knowledge. The subgame perfect equilibrium (SPE) concept will be used to characterize the strategies and outcome of this game. ${ }^{7}$

Definition 1. A strategy pair is a SPE if the strategy pair it induces in every subgame is a Nash equilibrium of that subgame.

Definition 2. A peaceful SPE is an SPE in which war never occurs in any subgame.

Proposition 1 (Commitment Problem). Let $\alpha \equiv\left(1+\delta_{B}\right) /\left(\delta_{B}\right)$ and $\beta \equiv\left(1-\delta_{B}\right) /\left(\delta_{B}\right)$. The game described in this section has no peaceful SPE if

$$
p(2)>\alpha p(1)+\beta c_{B} .
$$

The shift in power described in Proposition 1 is the essence of the commitment problem described in the literature. Because the rising state cannot credibly commit to any large concession in the next period, the declining one prefers fighting now.

\section{Solving the commitment problem}

The model presented in the previous section shows that large and rapid shifts in relative power can lead to war. However, this result relies on an implausible assumption, namely that states only negotiate over final outcomes. Yet, in most bargaining situations, players can negotiate over two types of objects: those that affect their utility directly (benefits), and those that affect it only insofar as they affect bargaining power (capabilities). Most existing models of war have only analyzed the equilibria

\footnotetext{
7 The choice to limit the analysis to the set of SPE is justified by the fact that the less restrictive Nash Equilibrium concept does not rule out non-credible threats or promises off the equilibrium path. In the present context, ruling them out is particularly important, as the essence of the problem is precisely the difficulty to make commitments credible.
} 
and efficiency of situations in which the players bargain over final outcomes (benefits). In this section, I make the determinants of future power themselves - what I refer to as 'resources' or 'capabilities' - objects of negotiation. By resources or capabilities, I mean objects (e.g. military resources) that affect a player's likelihood of winning in a conflict. This definition is more general than might appear at first, as it can incorporate any type of capabilities including not only material ones (e.g. military capabilities) but also intangible ones such as the distance to the border. For example, troops stationed close to the border can easily be modeled as a different capability from troops that are not ready to be deployed, and withdrawing troops is itself a concession of capabilities.

I analyze a modified bargaining model in which players bargain not only over the territory $X$, but also over a set of resources $R$ of size one. The share of resources that each state owns is what determines its likelihood of prevailing in war. More precisely, $A$ wins a war in period $t$ with probability $p^{t}=p\left(r^{t-1}\right)$, where $p:[0,1] \rightarrow[0,1]$ is continuous, non-decreasing in $r$, $p(0)=0$ and $p(1)=1$. Let $r^{0} \in[0,1]$ denote the initial distribution of $R$ (so $\left.p^{1}=p\left(r^{0}\right)\right)$. The protocol remains the same, except that an offer is now a pair $\left(x^{t}, r^{t}\right)$, where $r^{t} \in[0,1]$ denotes the share of $R$ that $A$ would control until period $t+1 .^{8}$ The game's payoffs are still defined as

$$
U_{i}=u_{i}\left(x_{i}^{1}\right)+\delta_{i} u_{i}\left(x_{i}^{2}\right) .
$$

Note that, for now, payoffs are not a function of $r^{t}$ (intuitively, cannons do not increase utility), and conversely that $r^{t}$ is not a function of $x^{t}$ (i.e. objects that affect utility do not affect power). This assumption may be restrictive in some contexts, and will be relaxed later. As before, there are two periods $(t=1,2)$, and in each period $t, B$ either accepts an offer $\left(x^{t}, r^{t}\right)$ or rejects it, in which case war starts.

\section{Proposition 2. All SPE are peaceful when players can negotiate over their} relative power.

This result shows that the commitment problem caused by large and rapid shifts in relative power, as identified by Powell (2004), can be avoided when transfers of capabilities are added as a dimension in the bargaining space. By giving up capabilities now, $B$ changes his expected maximization problem in the next period, and hence credibly commits to the agreement in the next period. The result holds no matter how large or rapid the power shift is. As a result, shifts in relative power alone cannot be a sufficient explanation for war.

\footnotetext{
${ }^{8}$ Hence, $1-r^{t}$ is $B$ 's share.
} 


\section{Negotiating over power in practice}

Although the previous section showed that states can often avoid commitment problems by negotiating over their relative power, have states historically really engaged in such negotiations? This section presents evidence that they have.

Avoiding shifts in power. Powell (2006) demonstrates convincingly that offense and first-mover advantages are special cases of commitment problems caused by rapid changes in power. ${ }^{9}$ By striking first, a state can significantly increase its chance of prevailing, and hence this is a situation in which rapid changes in power - or at least the anticipation thereof lead to war. If concerns about a preemptive attack are what prevents efficient bargaining, however, the players should be willing to alleviate the other's fears by voluntarily limiting their ability to launch such an attack. For example, the parties can remove their troops from the border, or create demilitarized zones. ${ }^{10}$ On 30 July 1914, for example, the French Prime Minister René Viviani ordered a 10-km troop withdrawal along the entire French-German border. ${ }^{11}$

They can also ease commitment problems through agreements that limit the stocks or range of offensive weapons (e.g. the 1987 Intermediate-Range Nuclear Forces Treaty between the United States and the Soviet Union), as well as by the removal of threatening weapons. Thus, the Cuban missile crisis is a case in which the bargaining power of the Soviet Union would have dramatically increased as soon as the missiles would have become operational. Direct conflict was avoided by negotiations over missiles - that is, explicitly over instruments of power. Similarly, Gorbatchev's 1988 unilateral

9 'When a state decides to bargain rather than attack, it is also deciding not to exploit the advantages to striking first. This decision effectively shifts the distribution of power in the adversary's favor by giving it the opportunity to exploit the advantage to striking first, and this shift can lead to war', p. 184.

10 Thus, the tensions between India and Pakistan following terrorist attacks on the parliament of India de-escalated following the October 2002 withdrawal of Indian and Pakistani troops from their common border (see e.g. 'India to Withdraw Troops from Pakistani Border', The Times of India 16 October 2002 and 'Pakistan to Withdraw Troops from Border with India', Kyodo News 21 October 2002). Similarly, in December 2005, Ethiopia withdrew some of its forces from the Eritrean border 'in the interests of peace' ('Ethiopia "to reduce" border force', BBC News 10 December 2005) and Ecuador and Peru withdrew troops from their disputed border in 1998 ('Ecuador and Peru withdraw troops from disputed border area', BBC News 22 August 1998). Examples of demilitarized zones include the Rush-Bagot treaty of 1817 between the United States and the United Kingdom; the demilitarized zones (DMZs) between Israel and Syria, Israel and Egypt, and Israel and Jordan following Israel's independence in 1948; the Korean DMZ was created in 1953.

${ }^{11}$ However, the order was to be reversed by General Joffre. See Tuchman $(1994,101)$ and Stoessinger $(2001,18)$. 
troop reduction of 500,000 men in Eastern Europe had the consequence of making a surprise attack almost impossible (Kydd 2005). ${ }^{12}$

Negotiations over power extend beyond immediate threats, however. Limitations on naval armaments, for example, address concerns about shifts in power over longer periods than the simple withdrawal of troops or offensive weapons mentioned above. A fleet takes time and is costly to build, and personnel need intensive training that cannot be improvised over a short period of time. ${ }^{13}$ With such agreements, states avoid deeper shifts in power by limiting growth in naval armaments. In the 18th century, for example, Choiseul - then France's minister for foreign affairs - chose to limit the reconstruction of the French Navy in order to avoid fear, and a possible preventive reaction from Britain. France did not seek superiority, or even parity, but rather purposefully maintained a fleet equal to two-thirds of the British one (Masson 1981). ${ }^{14}$

The Washington Naval Treaty of 1922 is a more recent example of states bargaining over power to ease tensions created by differentials in relative growth. After World War I, the British Empire had the world's largest and most powerful navy, although the United States, and to a lesser extent, Japan were following closely. More concerning for Britain, the United States had announced its goal to create a navy 'second to none', whereas Japan was actively increasing the size of its fleet. Furthermore, the United States' economic power surpassed that of the United Kingdom, and it would therefore not be long until the Royal Navy would fall behind. Contrary to common beliefs, naval rivalry led to strong tensions between the two countries. Buell (1922), a contemporary of the conference, writes for example:

The naval program of the United States, along with its refusal to join the League of Nations, naturally aroused the suspicion of England as to the impurity of American motives. It is certain that eventually the British Empire would have answered the challenge of the 'big navy' men in the United States. [...]. But such a struggle could be forestalled only by checking naval competition. (p. 147)

In hindsight, it is tempting to underplay the rivalry of two countries that ended up not going to war. Yet, strong tensions were palpable not only

${ }^{12}$ We thank an anonymous reviewer for suggesting this example.

13 See Coutau-Bégarie (1995) for a history of naval disarmament.

${ }^{14}$ A related case is the naval rivalry between Britain and Germany that preceded World War I. From 1912 to 1914 , both powers came to the conclusion that mutual restraint in the naval arms race was in their mutual interests. This was not, however, a strategy to avoid war (especially on Germany's end), but rather a way to end the escalation in spending which Britain had made clear would be pointless by systematically matching Germany's investments (Maurer 1992). 
with Japan but also with Britain - so much so that some even stated that 'the relations between the two countries are beginning to assume the same character as that between England and Germany before the war'. ${ }^{15}$

It is in this context that the United States called for a disarmament conference. The treaty reached in Washington in 1922 limits the naval armaments of its five signatories - the United States, Britain, Japan, France, and Italy. It was widely viewed as an attempt to ease the climate of tensions by limiting the arms race, and particularly the fast-growing Navy of the United States. ${ }^{16}$ Doing this even involved the destruction of 15 existing ships and 11 uncompleted ones. In the words of Secretary of State Stimson,

The United States [...] was engaged in building a fleet of battleships larger and more powerful than those of any other nation in the world. [...]. In order to stop naval competition and to put an end to the consequent rivalry, suspicion, and fear between the nations which would grow out of such competition, America destroyed all of those new ships, together with thirteen older battleships in her possession. ${ }^{17}$

Still, one could object that preemptive wars almost never happen (Reiter 1995), and hence that this whole argument is largely irrelevant. However, the fact that this type of wars happens only rarely could actually be in support of the argument that states do negotiate over their relative power, precisely to avoid 'powder keg' situations. In other words, it is because states negotiate over their relative power that potentially dangerous situations in which a state might be tempted to preempt never emerge in the first place.

Avoiding potential shifts. Negotiations over power are not limited to disarmament agreements. States also negotiate over deeper causes of power shifts. In the 18th and 19th centuries, for example, 'compensations' (typically territorial ones) were frequently relied upon to maintain a balance of power that would have been upset by the growth of one nation.

15 House to Wilson, 30 July 1919, in Seymour (1926, Vol. IV, 510). Quoted in McKercher (1990). Also: 'a war with America would indeed be the most futile and damnable of all, but it is not "unthinkable", and we shall the more surely avoid it by cutting that word from our vocabulary. If it is childish - and it is - to suppose that two nations must forever be enemies, it is also childish to stake one's whole existence on the gamble that two must be forever friends (especially when they never have been really)'. (Vansittart (Head, Foreign Office American Department) minute, 15 September 1927, Austen Chamberlain MSS (Foreign Office Archives, Public Record Office, London) FO 800/261. Quoted in McKercher 1990.)

${ }^{16}$ See Roskill $(1968,1976)$ for a detailed history of naval policy in the interwar period.

17 Radio address by Henry L. Stimson from London, 28 January 1930, in 'London Naval Conference: Speeches and Press Statements by Members of the American Delegation, Conference Series 3 (Washington, DC: United States Government Printing Office, 1930), p. 6. Quoted in Lamb (1988). 
By sharing territory - a latent source of power - more or less equally among relevant players, this system avoided rapid shifts in relative power, and equally important, potential future shifts in relative power. Consider, for example, Catherine II's campaign of 1769 against Turkey. The campaign had been a large success, so much so that leaders of Prussia and Austria started to fear the rapid change in power that a victory would afford Russia. Moldavia and Wallachia were taken by the end of 1769 , and these victories represented a menace to Austria's eastern border. ${ }^{18}$ Kaunitz, then minister of foreign affairs, declared for example that it would be impossible to sit by and see the balance of power destroyed by these rapid successes (Kaplan 1962). ${ }^{19}$ Russia considered different options to compensate Austria for its loss of relative power, and the tumultuous internal affairs in Poland provided an opportunity for exploitation. In this case, the object of negotiations is not simply the distribution of armament, but rather the distribution of territory, precisely because territory is an instrument of future power. The concern for Austria was not Russia's aggrandizement per se, but what this increase in territory would mean for its long-term relative power and its ability to maintain the balance of power. The partition of Poland, by compensating Austria territorially, restored the balance of latent power.

A second example of negotiations over the roots of power and the prevention of long-term shifts is the creation of the European Coal and Steel Community (ECSC). It had become obvious by 1945 that arms control deals - negotiations over power itself - in the 1930s had either failed to materialize, or failed to prevent the rise of Germany. Hence, if another war was to be avoided, a deeper commitment mechanism would have to be created; potential shifts, not just shifts, would need to be regulated. By controlling coal and steel production - two central pillars of war - the aim of the ECSC was precisely to 'make war not only unthinkable but materially impossible'. ${ }^{20}$ To achieve this goal, Europe's first supranational community was formally established by the Treaty of Paris (1951), uniting the two industries across its main signatories, France and Germany. The Treaty delegated monitoring and enforcement power to a High Authority, which could punish deviations with fines. Of course, this power was ultimately limited, as the High Authority did not have the physical ability to enforce

${ }^{18}$ See Kaplan (1962) for an analysis of the first partition of Poland (see pp. 121-30 in particular).

${ }^{19}$ Kaplan also shows direct evidence that 'if Russia continued to be obstinate and push her advantage, war with Austria was inevitable. The penetration of Russian troops deep into the Danube basin or the determination of Russia to make Poland a province of her empire would be sufficient cause for Austria's intervention' (p. 127).

${ }^{20}$ Robert Schuman. Declaration of 9 May 1950. 
the agreement. Yet, monitoring alone would provide early warnings about deviations, and the precision of the agreement would demonstrate that any sustained deviation was voluntary, thereby signaling hostile intentions to the other party. The advantage of this agreement is that it did not bridle Germany's economic growth as the Versailles treaty had. Rather, it simply ensured that this growth would not lead to uncontrollable shifts in relative power between France and Germany. To be sure, the ECSC's goal was not only to offer guarantees against future armament; it was also to establish a preferential trading zone with gradual adjustment among its members - an institutionalized cartel. Nevertheless, the choice of coal and steel - as opposed to, say, agriculture - as well as its intended audience (Schuman's initial proposition was targeted at France and Germany) ${ }^{21}$ makes it clear that the intentions of its founders were not purely economic efficiency (although this was clearly valued) but also the creation of guarantees against relative shifts in power between its main members, France and Germany.

Overall, although there are numerous instances of negotiations over power, it is likely that the true number of cases of transfers of power is actually far larger. Indeed, if it is expected that a shift in power will create tensions and increase the risk of war, then the states might never actually spend the effort needed to grow to that level. In arms races, for example, the quantity of arms built is not defined exogenously, but rather is chosen as a function of the expected response of the opponent. Similarly, most calculations of conquest incorporate the perception by other states of the appropriateness of the implied change in the balance of power. The decision to conquer includes at least two main considerations: first, that the object of conquest is worth more than its costs and risks; and second, that third parties will not fight to prevent the increase in power it might generate. In other words, states will exert restraint in their conquests and their armament, so that many large and rapid shifts in power are averted quietly, and not explicitly as the result of negotiations. Because of this selection bias, negotiations over power appear to be far fewer than they actually are, simply because many occur informally or implicitly.

\section{Why war might still occur}

We now look for potential reasons why the mechanism highlighted above might not be feasible or applicable. In other words, could war still occur despite the ability to negotiate over sources of power?

21 'Franco-German production of coal and steel as a whole [should] be placed under a common High Authority, within the framework of an organization open to the participation of the other countries of Europe'. 


\section{Limits on the ability to affect tomorrow's power}

The commitment mechanism detailed in section 'Negotiating over power' might fail if the parties are unable to trade capabilities. First, the implicit assumption has been that sources of power such as territory or population do matter. This is debatable if we agree with, among others, Rosecrance's argument that land is becoming less valuable than technology or knowledge (Rosecrance 2000), or Biddle's case that a significant portion of power originates from military strategy and doctrine (Biddle 2004). Capabilities such as resolve, military training, morale, knowledge, or experience are typically impossible to give up or transfer. As a result, the rising player might be unable to set his capabilities to the level necessary to satisfy the declining power (e.g. setting $r^{t}$ close to zero could be infeasible). In practice, however, this theoretical difficulty is less serious than it might appear. Immaterial factors certainly play an important role, but mostly so in combination with material capabilities. Resolve alone does not win a war; it does increase the value of each material unit of power, but does not generate power by itself. As a result, immaterial capabilities do not imply that power is not negotiable or cannot be set to specific levels as needed. ${ }^{22}$ In other words, although material assets such as territory or population do not determine power - compare Brazil with Great Britain - they constitute a necessary basis for it. Luxembourg, for all its technology and integration in world trade, will certainly never been able to rival with Russia in terms of military power.

In addition, capabilities are not always perfectly divisible, or almost equivalently, the function $p(\cdot)$ might exhibit discontinuities. The existence of a smallest capability unit or of discontinuities - consider, for example, a state's acquisition of its first nuclear weapon ${ }^{23}$ - can cause war, as the appeaser might not be able to tailor his level of capabilities sufficiently precisely to satisfy the other player (Fearon 1996). In this case, the rising state faces the choice of making either too large a concession in which case he becomes the one facing a commitment problem - or an insufficient one, which does not deter the declining state from going to war. $^{24}$

${ }^{22}$ For example, power might be conceptualized as a function of capabilities of the form $p=M^{a} I^{1-a}$, where $a>0$ and $M$ denotes material capabilities and $I$ immaterial ones. When the function that relates capabilities to the chance of winning (power more generally) takes this form, setting $p$ to any number remains possible simply by changing material capabilities $M$.

${ }^{23}$ I thank an anonymous reviewer for this example.

${ }^{24}$ A similar argument has been made in the context of imperfectly divisible pies as a cause of war (Fearon 1995; Walter 2000; Toft 2003; Goddard 2006). Interestingly, Smith and Stam (2001) find that divisible stakes can, on the contrary, increase the likelihood of wars. 


\section{Negotiating over deeper power shifts}

Another possible objection to the feasibility of negotiations over power is that, although it is possible to negotiate over tangible, direct sources of power - tanks, ships, the distance of troops to the border - it might be difficult to negotiate over more fundamental aspects of power. In other words, the mechanism presented might not alleviate the deeper concerns of the declining state: even if the rising state gives up a number of tanks, or even a ship-building program, her domestic growth remains such that she will still become much more powerful in the long term. The benefits of destroying ships, say, would only be temporary and not address the deeper causes of the problem. In modeling terms, the challenge is that power is not only affected by $r$ (resources and capabilities) but also by $x$ (benefits). For example, a larger territory means the ability to extract more raw materials and to construct more factories. This means that the distribution of benefits agreed upon itself affects future power, and this should be taken into account in our model.

The extent to which benefits $(x)$ affect capabilities $(r)$ is an empirical matter (see the discussion below). For our purposes, however, assume the most difficult case, namely that any increase in benefits increases resources by the same amount, and vice-versa. Money, for example, is fungible into both benefits and capabilities. How is the efficiency result obtained in section 'Solving the commitment problem' affected when benefits overlap with capabilities? I show that bargaining can break down into war if the concessions necessary to satisfy $A$ today imply too large a loss of utility. China, for example, might not be willing to reduce its economic growth simply to reassure its neighbors.

To see why war might occur when there is no distinction between capabilities and benefits, consider a model in which $A$ and $B$ negotiate over a territory $X$ according to the same take-it-or-leave-it protocol. This time, however, $A$ wins a war with probability $p^{t}=p\left(x^{t-1}\right)$, instead of $p^{t}=p\left(r^{t-1}\right)$ as was the case in the previous model. ${ }^{25}$ Intuitively, this means that issues that affect utility (e.g. territory) also affect the probability of winning a war (a territory can be used for a larger population and hence army, or for a larger production base). As before, $p(\cdot)$ is continuous, $p(0)=0$, and $p(1)=1$.

This setup is essentially the same as that of Fearon (1996), with the exception that here the players' discount factors are not assumed to be equal - in other words, states can value the future differently. Surprisingly, this simple variation leads to a drastically different result: war can occur

${ }^{25}$ Again, $p_{A}^{t}=p\left(x^{t-1}\right)$ and $p_{B}^{t}=1-p\left(x^{t-1}\right)$. 
in equilibrium when $p$, the function that maps a share of territory into a probability of winning, is sufficiently steep, which indirectly means that growth rate differentials are large.

Proposition 3. Let $x_{A}^{2}\left(x^{1}\right) \equiv 1-x_{B}^{2}\left(x^{1}\right)$, where $x_{B}^{2}\left(x^{1}\right) \equiv u_{B}^{-1}\left(1-p\left(x^{1}\right)-c_{B}\right)$. There is no peaceful SPE if there exists no $x^{1} \in[0,1]$ such that, for all $i \in\{A, B\}$,

$$
u_{i}\left(x_{i}^{1}\right)+\delta_{i} u_{i}\left(x_{i}^{2}\left(x^{1}\right)\right) \geqslant\left[1+\delta_{i}\right] p_{i}^{1}-c_{i}
$$

In other words, the surprising result that war never occurs even when states negotiate over objects that affect future power (Fearon 1996) does not hold if we allow states to value the future differently. The intuition behind the result is the following. Suppose that $A$ anticipates a large shift in power in her disfavor. This means that for any $x^{t}, p\left(x^{t}\right)$ - her power in the next period - will be low. To compensate for this expected loss, $A$ asks today for a large $x^{t}$. If her power is declining rapidly, then she will need a very large $x^{t}$ today to ensure that her power tomorrow (and hence her share of the territory) will be sufficiently large. But if $B$ has a high value for his present share of the territory, then such a large concession in view of tomorrow is not acceptable, and $B$ prefers fighting.

In other words, the implementation of peaceful bargaining solutions such as the one proposed in Fearon (1996) is more difficult when the rising state does not value the future as much as the declining one. This is because different discount rates prevent the parties from smoothening their consumption of territory over time. For example, when $B$ does not discount the future too much, he can offer $A$ a large share of the pie today, because his growth rate implies that tomorrow its power will have increased again. In other words, $B$ is willing to appease $A$ today, because he knows that his power tomorrow will have increased and hence its benefits then will compensate the concessions made today. But if $B$ does not value tomorrow as much as $A$, then he is unwilling to make large concessions today. In the extreme case in which $B$ does not value the future at all, $B$ will not make any concession today, which implies for $A$ a large expected decline in power. This would be fine if $A$ did not value the future either (i.e. equal discount rates), but if she does, then she is willing to fight to prevent this outcome.

It should be noted that the empirical interpretation of this result is problematic, as discount rates are not readily observable and mapping them onto regimes is hence a perilous exercise. Intuitively, leaders of autocratic regimes should be more patient than those of democracies (Haggard and Kaufman 1995; Mansfield et al. 2002), and we would 
therefore expect shifts in power between democracies and autocracies to be more likely to lead to war. More precisely, the most dangerous situation would be that of a declining autocracy - that is, a player who values the future - and a rising democracy - an impatient player unwilling to make temporary concessions to the declining state. Unfortunately, validating this hypothesis empirically would require the ability first to measure discount rates and second to separate the effect of parallel explanations, such as those based on the democratic peace.

\section{Beyond bilateral bargaining}

Another difficulty arises in situations involving more than two players. Indeed, $B$ does not only weaken itself in relation to $A$ when it reduces the size of its army but also in relation to $C$. In other words, giving up capabilities to satisfy $A$ also reduces $B$ 's share of the territory with $C$. In some contexts, the cost generated by this reduction in capabilities can surpass the relative gains achieved by not fighting with $A$, so that fighting can occur in equilibrium.

Although an analysis of a realistic three-player game is well beyond the scope of this article, a simplified model is described here (see Appendix for a more formalized version and proofs). Suppose that there are three players $A$, $B$, and $C$, but assume for simplicity that $A$ and $C$ do not interact (they might be geographically too remote from one another and not be able to project power so far). We also exclude the possibility to form alliances, as their addition would complicate the model so much that its analysis is reserved for a separate article. These assumptions are clearly restrictive and unrealistic, but we simply hope to emphasize how the introduction of a third player can be an obstacle to the commitment mechanism presented above not to make a general statement about three-player games. Alliances might change the dynamic highlighted, but it is first important to understand the effect of each theoretical addition to the model.

Consider one of the simplest possible game. Suppose that there are two periods with identical protocols. In each of them, $A$ and $B$ negotiate over a territory, then $B$ and $C$ negotiate over another territory. Suppose moreover that $C$ is declining. To avoid war with $C$ in the first round, then $B$ must make some concessions to $C$ so that the expected balance of power in the second round will be maintained between them (at least within certain bounds). However, this also means that $B$ 's power in relation to $A$ will have decreased, so that $B$ will receive less from $A$ in stage 2 . In fact, the more $C$ is declining, the more concessions $B$ needs to make to appease it, and these concessions have a cost for $B$ when it faces $A$ in the next period. If this reduction in power is too costly for $B$ (because 
they hinder $B$ 's negotiating power against $A$, and the territory negotiated with $A$ might matter more than the one with $B$ ), or if a war with $C$ in the first round is relatively cheap, then war can be rational in equilibrium, despite complete information and the ability to negotiate over sources of relative power. Appendix provides a simple formalized model of this intuition.

This result shows that even when states can negotiate over the determinants of their power, there exist structural difficulties that can reduce and even suppress the zone of agreement. Although the commitment problem in the bilateral case could be solved by adding the possibility of negotiating over power shifts themselves, there is no clear way to prevent war here. In fact, the problem is compounded by a large number of players. If $B$ also shares territories with $D$ and $E$, then the initial concession to $C$ will lead to substantial losses of influence with respect to a large number of players in the next period. Hence, as the number of partners increases, the relative cost of concessions to $C$ increases, thereby widening the range of parameters for which war occurs in equilibrium.

\section{Domestic constraints}

Domestic politics constitute a third set of constraints on the ability to negotiate over power. First, conceding power can be politically costly for leaders, because its sources - capabilities or territories, for example often have intrinsic religious or ideological value, beyond their economic or military purpose. This is perhaps best illustrated by the 1930 assassination attempt against Japanese Prime Minister Hamaguchi. His signature of the London Naval Agreement - a follow-up to the Washington agreement of 1922 - was perceived by many right-wing politicians and the army as a treason to Japan's growing world influence.

Another challenge of domestic politics are commitment problems caused by shifts in leadership. Suppose, for example, that there exists some positive probability of an irrational leader taking power. Then, the guarantees offered by the current government and the schedule of power reduction agreed upon might be insufficient to ease the concerns of the declining state. Irrationality need not be the only concern of that state: the emergence of a leader who values military objects for their own sake - as might be the case for a military faction - could mean that the schedule of military reduction would be undermined under the new leadership. In other words, the problem of commitment caused by large and rapid shifts in relative power can be compounded by another commitment problem caused by the inability of leaders to guarantee a certain policy course over extended periods of time (see also Wolford 2007). 


\section{Conclusion}

A prevalent argument in the literature on international relations is that rapid shifts in relative power create tensions that can lead to war. When relative power changes over time, the declining state worries that the rising one will exploit its increased strength in the future. If the shift is sufficiently large and rapid, the declining state prefers fighting now to avoid bargaining tomorrow in a weaker position. Even though the present analysis has focused on interstate wars, this inefficiency is not specific to international politics. Thus, in civil wars, rebels fear that the government will exploit their weakness once they have dropped their weapons. In domestic politics, the outgoing leader prefers engraving his policies into inefficiently rigid institutions to protect them from his successor's changes. In each case, there exist agreements that both parties would prefer to fighting, but the inability of the rising player to commit to any behavior once it is stronger prevents them from being reached.

To avoid inefficiency, then the challenge is for the rising party to find a way to credibly commit to not exploiting the declining state in the future. This paper is a first attempt at understanding the conditions under which this is possible. I found that concessions of capabilities solve the commitment problem, and hence that large and rapid changes in relative power in the dyad alone cannot be a sufficient explanation for war.

The second contribution of this paper is to point out the conditions under which negotiations over capabilities might not be feasible. In particular, three main limitations stand out. First, states might be negotiating over objects that affect their future power. Second, although the rising state might be willing to reduce its power to alleviate the fears of the declining one, doing so might be too costly if it implies a loss of power in relation to third parties. Using a highly stylized model, this article showed that this mechanism can indeed lead to war, even when the parties can negotiate over their relative power. Finally, domestic politics can stand in the way of negotiations, for example if domestic audiences value power for the prestige it confers, or if changes in leaders undermine the ability to strike credible deals over time.

\section{Acknowledgements}

I would like to thank Bob Axelrod, James Fearon, Shanna Kirschner, Ken Kollman, Jim Morrow, Branislav Slantchev, participants at the University of Michigan Internal Speaker Series, and three anonymous reviewers for helpful comments and suggestions. 


\section{References}

Acemoglu, Daron, and James Robinson. 2000. "Why Did the West Extend the Franchise? Democracy, Inequality and Growth in Historical Perspective." Quarterly Journal of Economics 115(4):1167-99.

Biddle, Stephen. 2004. Military Power: Explaining Victory and Defeat in Modern Battle, Princeton, NJ: Princeton University Press.

Bijian, Zheng. 2005. "China's 'Peaceful Rise' to Great-Power Status.” Foreign Affairs 84(5):18-24.

Buell, Raymond. 1922. The Washington Conference, New York, NY: Appleton and Company. Coutau-Bégarie, Hervé. 1995. Le Désarmement Naval. Paris: Economica.

DiCicco, Jonathan M., and Jack S. Levy. 1999. "Power Shifts and Problem Shifts: The Evolution of the Power Transition Research Program." Journal of Conflict Resolution 43(6):675-704.

Fearon, James. 1995. "Rationalist Explanations for War." International Organization 49(3):379-414.

— 1996. "Bargaining Over Objects that Influence Future Bargaining Power." Annual meeting of the APSA, Washington, DC.

Ferguson, Niall. 1999. The Pity of War: Explaining World War I, London: Penguin Books.

2006. The War of the World: Twentieth-Century Conflict and the Descent of the West, London: Penguin Books.

Fuerst, Philipp. 2009. "Preventing Preventive Wars with Signals of Reassurance.” Paper presented at the annual meeting of the Midwest Political Science Association, Chicago, IL.

Gilpin, Robert. 1981. War and Change in World Politics, Cambridge, MA: Cambridge University Press.

Goddard, Stacie E. 2006. "Uncommon Ground: Indivisible Territory and the Politics of Legitimacy." International Organization 60(1):35-68.

Haggard, S., and R.R. Kaufman. 1995. The Political Economy of Democratic Transitions, Princeton, NJ: Princeton University Press.

Hartzell, Caroline A. 1999. "Explaining the Stability of Negotiated Settlements to Intrastate Wars." Journal of Conflict Resolution 43(1):3-22.

Hoddie, Matthew, and Caroline Hartzell. 2003. "Civil War Settlements and the Implementation of Military Power-Sharing Arrangements." Journal of Peace Research 40(3): 303-20.

Hoge, James F. 2004. "A Global Power Shift in the Making." Foreign Affairs 83(4):2-7.

Joll, James. 1992. The Origins of the First World War, London: Longman.

Kaplan, Herbert. 1962. The First Partition of Poland. New York, NY: Columbia University Press.

Kim, Woosang. 1992. "Power Transitions and Great Power War from Westphalia to Waterloo." World Politics 45(1):153-172.

Kydd, Andrew. 2005. Trust and Mistrust in International Relations, Princeton, NJ: Princeton University Press.

Kydland, Finn E., and Edward C. Prescott. 1977. "Rules Rather than Discretion: The Inconsistency of Optimal Plans." Journal of Political Economy 85(3):473-492.

Lamb, Christopher. 1988. How to Think About Arms Control, Disarmament, and Defense, Englewood Cliffs, NJ: Prentice Hall.

Mansfield, E.D., H.V. Milner, and B.P. Rosendorff. 2002. "Why Democracies Cooperate More: Electoral Control and International Trade Agreements." International Organization 56(03):477-513.

Masson, Philippe. 1981. Histoire de la Marine - Tome I: L'ère de la voile, Paris: Charles Lavauzelle.

Maurer, J.H. 1992. "The Anglo-German Naval Rivalry and Informal Arms Control, 1912-1914." Journal of Conflict Resolution 36(2):284. 
McKercher, B.J.C. 1990. Anglo-American Relations in the 920's: The Struggle for Supremacy, Edmonton, AB: University of Alberta Press.

Mearsheimer, John J. 2006. “China's Unpeaceful Rise.” Current History 105(690):160.

Morrow, James D., and Woosang Kim. 1992. "When Do Power Shifts Lead to War?” American Journal of Political Science 36(4):896-922.

North, Douglass C., and Barry R. Weingast. 1989. "Constitutions and Commitment: The Evolution of Institutions Governing Public Choice in Seventeenth-Century England." Journal of Economic History 49(4):803-832.

Organski, Abramo F.K. 1958. World Politics, New York, NY: Alfred A. Knopf.

Powell, Robert. 1999. In the Shadow of Power: States and Strategies in International Politics. Princeton, NJ: Princeton University Press.

— 2004. "The Inefficient Use of Power." American Political Science Review 98(2): 231-241.

— 2006. "War as a Commitment Problem." International Organization 60(1):169-203.

Reiter, Dan. 1995. "Exploding the Powder Keg Myth: Preemptive Wars Almost Never Happen.” International Security 20(2):5-34.

2009. How Wars End. Princeton, NJ: Princeton University Press.

Rosecrance, R.N. 2000. The Rise of the Virtual State: Wealth and Power in the Coming Century, New york, NY: Basic Books.

Roskill, Stephen. 1968. Naval Policy Between the Wars: Vol. I - The Period of Anglo-American Antagonism, 1919-1929, London: Collins.

— 1976. Naval Policy Between the Wars: Vol. II - The Period of Reluctant Rearmament, 1930-1939, London: Collins.

Russett, B. 1990. Economic Decline, Electoral Pressure, and the Initiation of Interstate Conflict. In Prisoners of War? Nation States in the Modern Era, edited by Charles S. Gochman and Alan Ned Sabrosky, 123-140, Lexington, MA: D.C. Heath and Co.

Seymour, Charles. 1926. The Intimate Papers of Colonel House. Boston, MA: Houghton Mifflin. Smith, Alastair, and Allan Stam. 2001. "Issues, Stakes and the Nature of War." Annual meeting of the American Political Science Association, San Francisco, CA.

Stoessinger, John G. 2001. Why Nations Go to War, 8th ed. New York, NY: St. Martin's Press. Taylor, Allan J.P. 1954. The Struggle for Mastery in Europe, 1848-1918. New York, NY: Oxford University Press.

Thucydides. 1984. The Peloponnesian War, New York, NY: Penguin.

Toft, Monica. 2003. "Indivisible Territory, Geographic Concentration, and Ethnic War." Security Studies 12(2):82-119.

Tuchman, Barbara. 1994. The Guns of August, New York, NY: Ballantine Books.

Vagts, Alfred. 1956. Defense and Diplomacy: The Soldier and the Conduct of Foreign Relations, New York, NY: Kings Crown.

Van Evera, Stephen. 1999. Causes of War, Ithaca, NY: Cornell University Press.

Wagner, Robert Harrison. 2007. War and the State: the Theory of International Politics. University of Michigan Press, Ann Arbor, MI.

Walter, Barbara. 2000. "Explaining the Apparent Indivisibility of Territory." Paper presented at the American Political Science Association Annual Conference, Washington, DC.

— 2002. Committing to Peace: The Successful Settlement of Civil Wars, Princeton, NJ: Princeton University Press.

Wolford, Scott. 2007. "The Turnover Trap: New Leaders, Reputation, and International Conflict." American Journal of Political Science 51(4):772-788.

Wolford, Scott, Dan Reiter, and C. Carrubba. 2011. "Information, Commitment, and War." Journal of Conflict Resolution (Forthcoming). 


\section{Appendix. Proofs and additional results}

\section{A model with three players}

Consider a game in which there are three players, denoted by $i \in\{A, B, C\}$, and two pies, $X_{A B}$ and $X_{B C}$, where $X_{i j}$ denotes the territory shared by $i$ and $j$. For simplicity, we assume that $A$ and $C$ do not share a territory, and hence need not negotiate. ${ }^{26}$ We also exclude the possibility to form alliances, as their addition would complicate the model so much that we reserve its analysis for a separate article. These assumptions are clearly restrictive and unrealistic, but we simply hope to emphasize how the introduction of a third player can be an obstacle to the commitment mechanism presented above - not to make a general statement about three-player games. Alliances might change the dynamic highlighted, but it is first important to understand the effect of each theoretical addition to the model.

We consider one of the simplest possible game. There are two periods with identical protocols. In each period, first $A$ and $B$ negotiate over $X_{A B}$ following the take-it-or-leave-it protocol of the previous sections; ${ }^{27}$ then, $B$ and $C$ negotiate over $X_{B C}$ following that same protocol. As before, a war leads to the disappearance of the loser (with cost $-c_{i j}$ ), whereas the winner gains the use of $X_{i j}$ until the end of the game. Player $i$ 's share of $X_{i j}$ at time $t$ is denoted by $x_{i j}^{t}$ (hence $j$ 's share is $1-x_{i j}^{t}$ ). Probabilities of winning are given by $p_{i j}\left(x_{i}^{t-1}, x_{j}^{t-1}\right)$, where $x_{i}^{t-1}$ is the entire territory controlled by $i$ in the previous period (i.e. $x_{A B}^{t-1}$ for $A, 1-x_{A B}^{t-1}+x_{B C}^{t-1}$ for $B$ and $1-x_{B C}^{t-1}$ for $\left.C\right), \frac{\partial p_{i j}}{\partial x_{i}} \geqslant 0$, and $\frac{\partial p_{i j}}{\partial x_{j}} \leqslant 0$. The initial probabilities in the first period are exogenously given as $p_{i j}^{1} \in[0,1]$.

For simplicity of exposition, we also make a few modeling simplifications: we assume an identical discount factor $\delta$, risk neutrality, and pies of equal size (i.e. $\delta=\delta_{i}=\delta_{j}, u_{i}(z)=z$, and $X_{i j}=1$ for all $\left.i, j \in\{A, B, C\}\right){ }^{28}$ Furthermore, it will be convenient to introduce additional notation: let $\bar{p}_{A B}$ be $A$ 's probability of winning a war against $B$ after $B$ has $w o n$ a war against $C$ (i.e. when $B$ is strong): $\bar{p}_{A B} \equiv p_{A B}\left(x_{A B}^{1}, 2-x_{A B}^{1}\right)$; let $p_{A B}$ denote $A$ 's probability of winning after $B$ has lost a war against $C$ (i.e. when $B$ is weak): $\underline{p}_{A B} \equiv p_{A B}\left(x_{A B}^{1}, 1-x_{A B}^{1}\right)$; let $\bar{p}_{A B}$ be $A$ 's probability of winning after $B$ has reached an agreement with $\bar{C}: \underline{p}_{A B} \equiv p_{A B}\left(x_{A B}^{1}, x_{B C}^{1}+1-x_{A B}^{1}\right)$; and

${ }^{26}$ A number of reasons could explain this absence of interactions: lack of strategic interest in the other's territory; distance and inability to project power; etc.

27 That is, $A$ makes an offer that $B$ can reject. If $B$ rejects it, a war starts in which the winner gains the entire pie $x_{A B}$ until the end of the game.

28 The main conclusions can also be obtained without these simplifications, but at a great cost in terms of notation. 
let $\bar{p}_{B C} \equiv p_{B C}\left(x_{B C}^{1}+1-x_{A B}^{1}, 1-x_{B C}^{1}\right)$ be $B$ 's probability of winning against $C$ after reaching an agreement with $C$ in the first round.

To understand how war can occur in equilibrium, first note that, if war is to be avoided, $A$ 's offer to $B$ and $B$ 's offer to $C$ in the second period respectively $x_{A B}^{2}$ and $x_{B C}^{2}-$ must satisfy

$$
\begin{array}{lll}
1-x_{A B}^{2} \geqslant 1-\underline{\bar{p}}_{A B}-c_{B A} & \Rightarrow & x_{A B}^{2} \leqslant \underline{\bar{p}}_{A B}+c_{B A}, \\
1-x_{B C}^{2} \geqslant 1-\underline{\bar{p}}_{B C}-c_{C B} & \Rightarrow & x_{B C}^{2} \leqslant \underline{\bar{p}}_{B C}+c_{C B} .
\end{array}
$$

Moreover, $x_{B C}^{1}$ must be such that $C$ prefers accepting $x_{B C}^{1}$ to fighting, which is the case only if

$$
\begin{aligned}
& 1-x_{B C}^{1}+\delta\left(1-x_{B C}^{2}\right) \geqslant\left(1-p_{B C}^{1}\right)(1+\delta)-c_{C B} \\
& \Rightarrow \quad x_{B C}^{1} \leqslant(1+\delta) p_{B C}^{1}-\delta \underline{p}_{B C}+c_{C B}(1-\delta) .
\end{aligned}
$$

Rationality dictates that inequalities (4), (5), and (6) must hold with equality, so that $B$ 's payoff in the absence of any war is

$$
\begin{aligned}
& {\left[1-x_{A B}^{1}\right]+\left[x_{B C}^{1}\right]+\delta\left[1-x_{A B}^{2}\right]+\delta\left[x_{B C}^{2}\right]} \\
& \left.=\left[1-x_{A B}^{1}\right]+(1+\delta) p_{B C}^{1}\right)+c_{C B}+\delta\left[1-\underline{p}_{A B}-c_{B A}\right] .
\end{aligned}
$$

If, on the other hand, $B$ chooses to fight (more precisely, if it offers $C$ a share of $X_{B C}$ that $C$ rejects), then $B$ wins with probability $p_{B C}^{1}$ and goes on to the second period with additional territory, and hence more bargaining power against $A$. With probability $1-p_{B C}^{1}$, however, $B$ will lose and face $A$ in the second round with a weaker bargaining power. More formally, $B$ 's expected payoff for fighting $C$ in the first period is

$$
\left[1-x_{A B}^{1}\right]+p_{B C}^{1}\left(1+\delta\left(2-\bar{p}_{A B}-c_{B A}\right)\right]+\delta\left(1-p_{B C}^{1}\right)\left[1-\underline{p}_{A B}-c_{B A}\right]-c_{B C} .
$$

Hence, $B$ will prefer war when $(8)>(7)$, which is the case when

$$
\underline{\bar{p}}_{A B}>p_{B C}^{1} \bar{p}_{A B}+\left(1-p_{B C}^{1}\right) \underline{p}_{A B}+C, \quad \text { where } C \equiv \frac{c_{B C}+c_{C B}}{\delta} .
$$

The following proposition and its proof establish this result more formally.

Proposition 4. War occurs in equilibrium whenever

$$
\underline{\bar{p}}_{A B}>p_{B C}^{1} \underline{\bar{p}}_{A B}+\left(1-p_{B C}^{1}\right) \underline{p}_{A B}+C .
$$

Proof: See the 'Proofs' section below 
Not surprisingly, we note that war never occurs when $p_{B C}^{1}=0$, since $\underline{p}_{A B}<\underline{p}_{A B}$, but that as $p_{B C}^{1}$ increases, the conditions required for $B$ to prefer fighting become less stringent. ${ }^{29}$ More interestingly, note that condition 10 is easier to fulfill when $x_{B C}^{1}$ - the amount that $B$ needs to give $C$ to avoid war is small. A small $x_{B C}^{1}$ means that $B$ needs to concede a lot because it is growing fast - this is the essence of the commitment mechanism proposed earlier. However, a small $x_{B C}^{1}$ also has the effect of increasing $\bar{p}_{A B}$ ( $A$ 's power in the second period), and as a result the range of parameters for which war would occur. In other words, condition 10 states that the more $C$ is declining, the more concessions $B$ needs to make to appease it, but also that these concessions have a cost for $B$ when it faces $A$ in the next period. If this expected loss in the second period is too large, then fighting $C$ in the first period can yield a higher payoff than peace.

Proofs

Proof of Proposition 1. I show that war always occurs in period 1 if condition (2) holds. The proof proceeds by backward induction. First, note that in period 2, $B$ can always fight and guarantee a payoff of

$$
p(2) u_{B}(0)+[1-p(2)] u_{B}(1)-c_{B}=1-p(2)-c_{B} .
$$

This means that, in period $2, B$ cannot credibly threaten to reject an offer $x^{2}$ such that

$$
u_{B}\left(1-x^{2}\right) \geqslant 1-p(2)-c_{B}
$$

and will fight for any $x^{2}$ such that (11) does not hold. Rationality then requires that $A$ make an offer $x^{2}$ such that (11) holds with equality. ${ }^{30}$

Consider now incentives in period 1 . First, note that the most $A$ can possibly offer $B$ in period 1 is $x^{1}=0$. Accepting this offer yields for $B$ an expected utility of

$$
u_{B}(1)+\delta_{B}\left(1-p(2)-c_{B}\right)
$$

${ }^{29}$ More precisely, $B$ cannot decide to fight - this decision is $C$ 's. However, $B$ can offer $x_{B C}^{1}$ such that $C$ will reject the offer and fight.

${ }^{30}$ To see why this must be true, fix $B$ 's strategy and consider first an offer $x^{2^{\prime}}>x^{2}$. B will reject this offer $\left(\right.$ since $u_{B}(\cdot)$ is decreasing in $\left.x, u_{B}\left(1-x^{2^{\prime}}\right)<1-p(2)-c_{B}\right)$, and war occurs. Wars yields for $A$ an expected utility of

$$
u(1) p(2)+u(0)(1-p(2))-c_{A}=p(2)-c_{A} .
$$

But note that $x^{2} \geqslant p(2)+c_{B}$ since $u_{B}(\cdot)$ is concave, and hence $u_{A}\left(x^{2}\right) \geqslant p(2)+c_{B}$ by concavity of $u_{A}(\cdot)$. Since $c_{i}>0, u_{A}\left(x^{2}\right)>p(2)-c_{A}$, and hence offering $x^{2^{\prime}}$ cannot be a best response to $B$ 's strategy. Clearly, an offer $x^{2^{\prime \prime}}<x^{2}$ cannot be a best response either, since $B$ would accept $x^{2}$, and $u_{A}\left(x^{2^{\prime \prime}}\right)<u_{A}\left(x^{2}\right)$ since $u_{A}(\cdot)$ is increasing in $x$. 
Since $u_{B}(\cdot)$ is decreasing in $x$, this means that (12) is the highest payoff $B$ can possibly receive from accepting any offer. Hence, if (12) is strictly smaller than $B$ 's utility for fighting, then there is no offer from $A$ that $B$ will prefer to fighting, and hence war occurs in equilibrium. Recall that $B$ wins the entire territory for both periods with probability $1-p(1)$, so war occurs in equilibrium in period 1 if

$$
\left(1+\delta_{B}\right)[1-p(1)]-c_{B}>1+\delta_{B}\left(1-p(2)-c_{B}\right) .
$$

Simple algebraic manipulation of (13) yields condition (2).

Proof of Proposition 2. The proof that war never occurs in period 2 is straightforward, as it is the last period (see Fearon 1995 for a related proof). The equilibrium strategies for period 2 are as follows (see the proof of Proposition 1 for the logic of this argument): $B$ accepts any $x^{2}$ such that

$$
u_{B}\left(1-x^{2}\right) \geqslant 1-p\left(r^{1}\right)-c_{B},
$$

and $A$ offers $x^{2}$ such that (14) holds with equality.

I now prove that war never occurs in period 1 either. The proof is by contradiction. Assume that war occurs in equilibrium in period 1. This implies that $B$ rejected $A$ 's offer $\left(x^{1}, r^{1}\right)$. This can only be a best response if $B$ 's utility for fighting is greater than his utility for accepting $\left(x^{1}, r^{1}\right)$, which is the case if and only if

$$
u_{B}\left(1-x^{1}\right)+\delta_{B}\left(1-p\left(r^{1}\right)-c_{B}\right)<\left(1+\delta_{B}\right) p\left(r^{0}\right)-c_{B} .
$$

However, I now show that offering $\left(x^{1}, r^{1}\right)$ such that (15) holds cannot be a best response for $A$.

Let $x^{1 *}=p\left(r^{0}\right)$ and $r^{1 *}=r^{0}$. I now show that (i) in equilibrium, $B$ 's strategy is to accept $\left(x^{1 *}, r^{1 *}\right)$ and (ii) that given $B$ 's strategy, $A$ 's expected utility from offering $\left(x^{1 *}, r^{1 *}\right)$ is greater than her expected utility from offering any $\left(x^{1}, r^{1}\right)$ that $B$ would reject (i.e. any $\left(x^{1}, r^{1}\right)$ such that (15) holds), and hence that making such an offer cannot be an equilibrium strategy.

(i) First, note that $B$ 's payoff for accepting $\left(x^{1 *}, r^{1 *}\right)$ is

$$
\begin{aligned}
& u_{B}\left(1-x^{1 *}\right)+\delta_{B}\left(1-p\left(r^{1 *}\right)-c_{B}\right) \\
& \geqslant 1-p\left(r^{0}\right)+\delta_{B}\left(1-p\left(r^{0}\right)-c_{B}\right) \quad \text { by concavity of } u_{B}(\cdot) \\
& =\left(1+\delta_{B}\right)\left[1-p\left(r^{0}\right)\right]-\delta_{B} c_{B} .
\end{aligned}
$$

Since (16) is at least as large as $B$ 's expected utility for war (because $\left.\delta_{B}<1\right), B$ will always accept $\left(x^{1 *}, r^{1 *}\right)$ in equilibrium.

(ii) It remains to be seen whether $A$ would want to make such an offer. To see that it would, consider $A^{\prime}$ s expected utility for offering $\left(x^{1 *}, r^{1 *}\right)$, 
given $B$ 's strategy. Since $u_{B}(\cdot)$ is weakly concave, $A$ obtains at least $p\left(r^{1 *}\right)+c_{B}$ in period 2 (cf. Equation 14). Hence, A's expected utility from offering $\left(x^{1 *}, r^{1 *}\right)$ is

$$
\begin{array}{lr}
u_{A}\left(x^{1 *}\right)+\delta_{A}\left[p\left(r^{1 *}\right)+c_{B}\right] & \\
\geqslant u_{A}\left(p\left(r^{0}\right)\right)+\delta_{A}\left[p\left(r^{0}\right)+c_{B}\right] & \text { by concavity of } u_{B}(\cdot) \\
\geqslant\left[1+\delta_{A}\right] p\left(r^{0}\right)+\delta_{A} c_{B} & \text { by concavity of } u_{A}(\cdot) \\
>\left[1+\delta_{A}\right] p\left(r^{0}\right)-c_{A} & \text { since } c_{i}>0 .
\end{array}
$$

This proves that offering $\left(x^{1}, r^{1}\right)$ such that $(15)$ holds cannot be a best reply, and hence that war never occurs in equilibrium.

Proof of Proposition 3. Assume that there exists no $x \in[0,1]$ that solves (3) for both $B$ and $C$. Then, I show that for any offer $x$, war occurs in equilibrium. To see this, note that for every $x \in[0,1]$, either

$$
u_{B}\left(1-x^{1}\right)+\delta_{B}\left[1-p\left(x^{1}\right)-c_{B}\right]<\left[1-p\left(x^{0}\right)\right]\left(1+\delta_{B}\right)-c_{B}
$$

or

$$
u_{A}\left(x^{1}\right)+\delta_{A} u_{A}\left(x^{2}\left(x^{1}\right)\right)<\left(1+\delta_{A}\right) p\left(x^{0}\right)-c_{A},
$$

or both.

Let $\bar{X}$ be the set of all $x$ such that only (17) is true. Then, if $A$ offers any $x \in \bar{X}, B$ can obtain a larger payoff by fighting, and hence war occurs in equilibrium with probability one.

Let $\underline{X}$ be the set of all $x$ such that only (18) is true. However, offering $x \in \underline{X}$ cannot be an equilibrium strategy for $A$. To see this, consider the following alternative strategy: $A$ offers $x^{t}=1$ for all $t \in\{1,2\}$ (and obviously, $1 \notin \underline{X}$ ). Then, $B$ rejects this offer and fights, yielding for $A$ an expected utility of $\left[1+\delta_{A}\right] p\left(x^{0}\right)-c_{A}$, so that $A$ 's expected utility from offering 1 is greater than from offering $x \in \underline{X}$, and war occurs as a result.

Clearly, a similar argument applies to any $x \in \bar{X}$, where $\overline{\bar{X}}$ denotes the set of all $x \in[0,1]$ such that both (17) and (18) hold. Since $\bar{X} \cup \underline{X} \cup \bar{X}=X$, this implies that for any offer $x \in X$, war occurs in equilibrium with probability one, and hence that there can be no peaceful SPE.

Proof of Proposition 4. Consider first the payoffs obtained in the second period for those states remaining. First, note that in the second period, $C$ accepts any $x_{B C}^{2}$ such that

$$
\begin{aligned}
& 1-x_{B C}^{2} \geqslant 1-\underline{\bar{p}}_{B C}-c_{C B} \\
& \Rightarrow \quad x_{B C}^{2} \leqslant \underline{\bar{p}}_{B C}+c_{C B} .
\end{aligned}
$$


Rationality then dictates that $B$ offers $x_{B C}^{2}$ such that (19) holds with equality. Similarly, in the second period, $B$ accepts any $x_{A B}^{2}$ such that

$$
x_{A B}^{2} \leqslant \underline{p}_{A B}+c_{B A} .
$$

In equilibrium, $A$ then offers $x_{A B}^{2}$ such that (20) holds with equality. It is easy to verify that war never occurs in equilibrium in round 2 .

In the first round, when it is $C$ 's turn to play, $C$ can always reject $B$ 's offer and obtain an expected utility of

$$
(1+\delta)\left(1-p_{B C}^{1}\right)-c_{C B} .
$$

On the other hand, accepting $B$ 's offer of $x_{B C}$ yields an expected utility of

$$
\begin{aligned}
& 1-x_{B C}^{1}+\delta\left[1-x_{B C}^{2}\right] \\
& \Rightarrow 1-x_{B C}^{1}+\delta\left[1-\underline{p}_{B C}-c_{C B}\right] .
\end{aligned}
$$

$C$ will accept any $x_{B C}^{1}$ that satisfies $(21) \leqslant(22)$, that is any $x_{B C}^{1}$ such that

$$
x_{B C}^{1} \leqslant(1+\delta) p_{B C}^{1}-\delta \underline{\bar{p}}_{B C}+c_{C B}(1-\delta) \text {. }
$$

Consider now $B$ 's decision in the first round, when it is its turn to make an offer. First, note that any offer $x_{B C}^{1}$ such that (23) holds with strict inequality cannot be rational, since $B$ can simply improve its payoff by offering $x_{B C}^{1}$ such that (23) holds with equality. Note also that any offer $x_{B C}^{1}$ such that (23) does not hold will be rejected by $C$. The problem, then, is to figure out whether such a rejection and the war that follows would lead to a higher payoff that offering $x_{B C}^{1}$ as defined in (23).

Consider first $B$ 's expected payoff after accepting $A$ 's offer $x_{A B}^{1}$ and offering $x_{B C}^{1}$ such that (23) holds with equality (we do not consider the case in which $B$ rejects $A$ 's offer, as this would imply war and hence trivially satisfy the proposition):

$$
\begin{gathered}
1-x_{A B}^{1}+x_{B C}^{1}+\delta\left[1-\underline{\bar{p}}_{A B}-c_{B A}\right]+\delta\left[\underline{\bar{p}}_{B C}+c_{C B}\right] \\
\Rightarrow(1+\delta)\left(1+p_{B C}^{1}\right)-x_{A B}^{1}-\delta \underline{\bar{p}}_{A B}+c_{C B}-\delta c_{B A} .
\end{gathered}
$$

Note now that $B$ 's payoff for offering $x_{B C}^{1}$ such that (23) does not hold (i.e. B's payoff for war with $C$ ) is to

$$
1-x_{A B}^{1}+p_{B C}^{1}\left[1+\delta\left(2-\bar{p}_{A B}-c_{B A}\right)\right]+\delta\left(1-p_{B C}^{1}\right)\left[1-\underline{p}_{A B}-c_{B A}\right]-c_{B C} .
$$

Thus, war occurs if $(24)<(25)$, that is if

where $C \equiv \frac{c_{B C}+c_{C B}}{\delta}$

$$
\underline{\underline{p}}_{A B}>\left[1-p_{B C}^{1}\right] \underline{p}_{A B}+p_{B C}^{1} \bar{p}_{A B}+C
$$

